\title{
Research on construction projects from a social network perspective: based on knowledge graph analysis
}

\author{
Jiaojiao Deng ${ }^{1}$, Chen Chen ${ }^{1, *}$, and Weichen Gong ${ }^{1}$ \\ ${ }^{1}$ Tianjin University of Technology, School of Management, 300384 Tianjin, China
}

\begin{abstract}
In order to comprehensively reflect the current status, research hotspots and evolutionary trends of research on construction projects from a social network perspective, 143 HJrelevant papers in the WoS database from 1999 to 2020 were taken as the research objects, and the bibliometric method and CiteSpace V were used to reveal the research development and evolution of the field during the 20 years and explore the future research trends. The study shows that the hotspots of construction project research from social network perspective include performance, governance, stakeholder management, risk management, and communication; research on construction project organizational network innovation, stakeholder risk and governance, BIM technology application, and social capital perspective to improve project organization become future research trends.
\end{abstract}

\section{Introduction}

Prior to the 1950 s, the binary relationship between owner and contractor served as the core two-party subject in project organization. Along with the increase in the number of project participants and other reasons, cooperation among project participants became a new research focus. At the same time, SNA has also been introduced into the construction project organization context with the emergence of management research under the social network paradigm. As the research continues to deepen and advance, the social network paradigm in construction project organization research is taking shape [1], relevant research results have been enriched ${ }^{[2,3]}$, but there is a lack of the latest quantitative literature research. In view of this, this study uses the relevant literature in the WoS database as research data, and systematically shows the current status of research, research hotspots and their evolution in this field through keyword co-occurrence and other indicators, and combined with visualization techniques.

\section{Research Data}

Using a structured approach, a two-stage search was conducted for literature related to the study of construction projects from an SNA perspective. In the first stage, a preliminary search was conducted. Given that the literature on the organization of construction projects from the SNA perspective was first published in $1997^{[4]}$, the time span of the search was set to 1997-2020, with "social network analysis \& construction projects", "social network analysis \& construction engineering", "social network analysis \& buildings", and "social network analysis \& project management" were used to search the peer-reviewed literature using data in the WoS database, and the actual search spanned from 1999 to 2020. A total of 1392 documents were obtained; in the second stage, data cleaning. After removing duplicate records and removing literature that did not involve SNA, 143 papers were finally identified.

\section{Analysis of research hotspots}

\subsection{Keyword co-occurrence analysis}

The high-frequency keywords and their interconnection can reflect the research hotspots in a specific research field to a certain extent. Delete the characterization keywords, merge the duplicate keywords, and select Keyword to run the program to generate the keyword co-occurrence network graph, as shown in Figure 1.

\footnotetext{
* Corresponding author e-mail: 1531956597@qq.com
} 


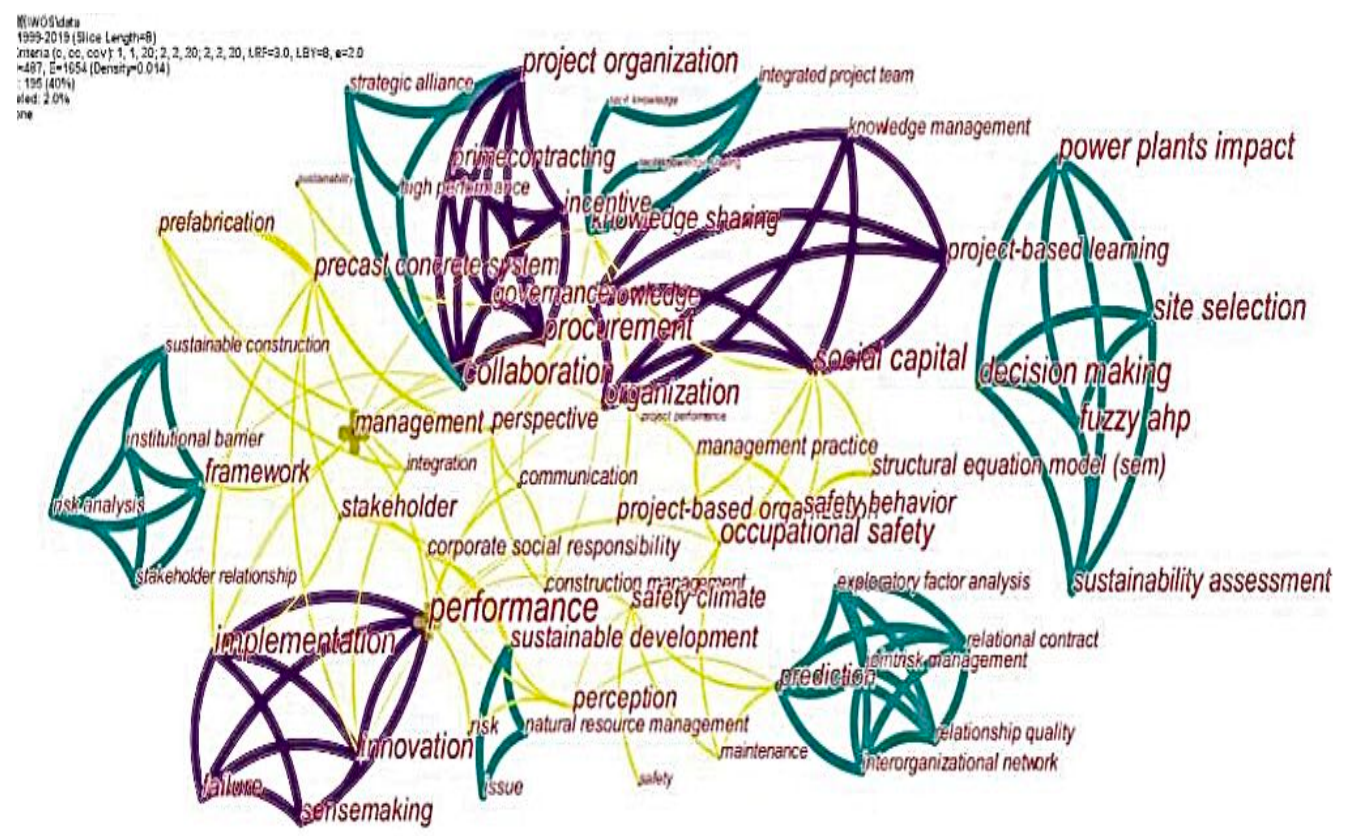

Figure 1 Keyword co-occurrence network

According to Figure 1, high frequency keywords as well as high centrality keywords were further counted and organized as shown in Table 1.

Table 1 High frequency keywords and high centrality keywords

\begin{tabular}{|c|c|c|c|c|}
\hline \multirow{2}{*}{$\begin{array}{c}\text { Sort } \\
\text { by }\end{array}$} & \multicolumn{2}{|c|}{ High Frequency Keywords } & \multicolumn{2}{|c|}{$\begin{array}{c}\text { High Centrality } \\
\text { Keywords }\end{array}$} \\
\cline { 2 - 5 } & $\begin{array}{c}\text { Keyword } \\
\text { Name }\end{array}$ & $\begin{array}{c}\text { Frequency of } \\
\text { co-occurrence }\end{array}$ & $\begin{array}{c}\text { Keyword } \\
\text { Name }\end{array}$ & Centrality \\
\hline 1 & performance & 53 & performance & 0.18 \\
\hline 2 & organization & 34 & governance & 0.15 \\
\hline 3 & $\begin{array}{c}\text { risk } \\
\text { management }\end{array}$ & 19 & Stakeholders & 0.13 \\
\hline 4 & communication & 17 & communication & 0.11 \\
\hline 5 & innovation & 15 & perception & 0.10 \\
\hline 6 & Stakeholders & 13 & barrier & 0.08 \\
\hline 7 & governance & 10 & knowledge & 0.06 \\
\hline
\end{tabular}

(1)"performance" ranked first in terms of frequency and centrality, and the discussion of project risk, communication, and stakeholder topics from the SNA perspective has been closely linked to project performance since the beginning, so "performance" became the keyword with the highest connection intensity and high influence. " becomes the keyword with the highest connection intensity and high influence. At the same time, construction project organizations are typically collaborative teams, and the close relationship between "communication" and information transfer, knowledge sharing, and task alignment has also gained extensive attention from researchers. The evolution of network collaboration patterns ${ }^{[5]}$, the analysis and measurement of communication patterns in projects from a network perspective ${ }^{[6]}$, and the optimization of team structure to balance communication in construction projects from the perspective of individual performance and characteristics are among the topics that have been discussed extensively under this keyword.

(2)The centrality ranking of "governance" and "takeholders" are both higher than the co-occurrence ranking, indicating that they are both major concerns in the field of construction project research. The literature on governance research in this field has remained at a high lever after a substantial increase since 2005.The introduction of the SNA perspective has opened up new perspectives and provided effective research methods for the study of relational governance in the context of informal organizational relationships in projects ${ }^{[7]}$ and also promoted the discussion of project governance as a whole ${ }^{[8]}$. And the research for stakeholders has also become the main topic of research on the organization of construction projects under the SNA perspective.

\subsection{Keyword clustering analysis}

In order to mine the connection between high-frequency keywords, the keywords were clustered and the LLR algorithm was used to extract the cluster naming, as shown in Figure 2. The Modularity Q value is 0.8038 and Mean Silhouette is 0.9773 , according to Modularity Q is greater than 0.3 means that the clustering structure is significant, when Mean Silhouette reaches 0.7 clustering is an efficient and credible judgment standard, the cluster is a high quality cluster. 


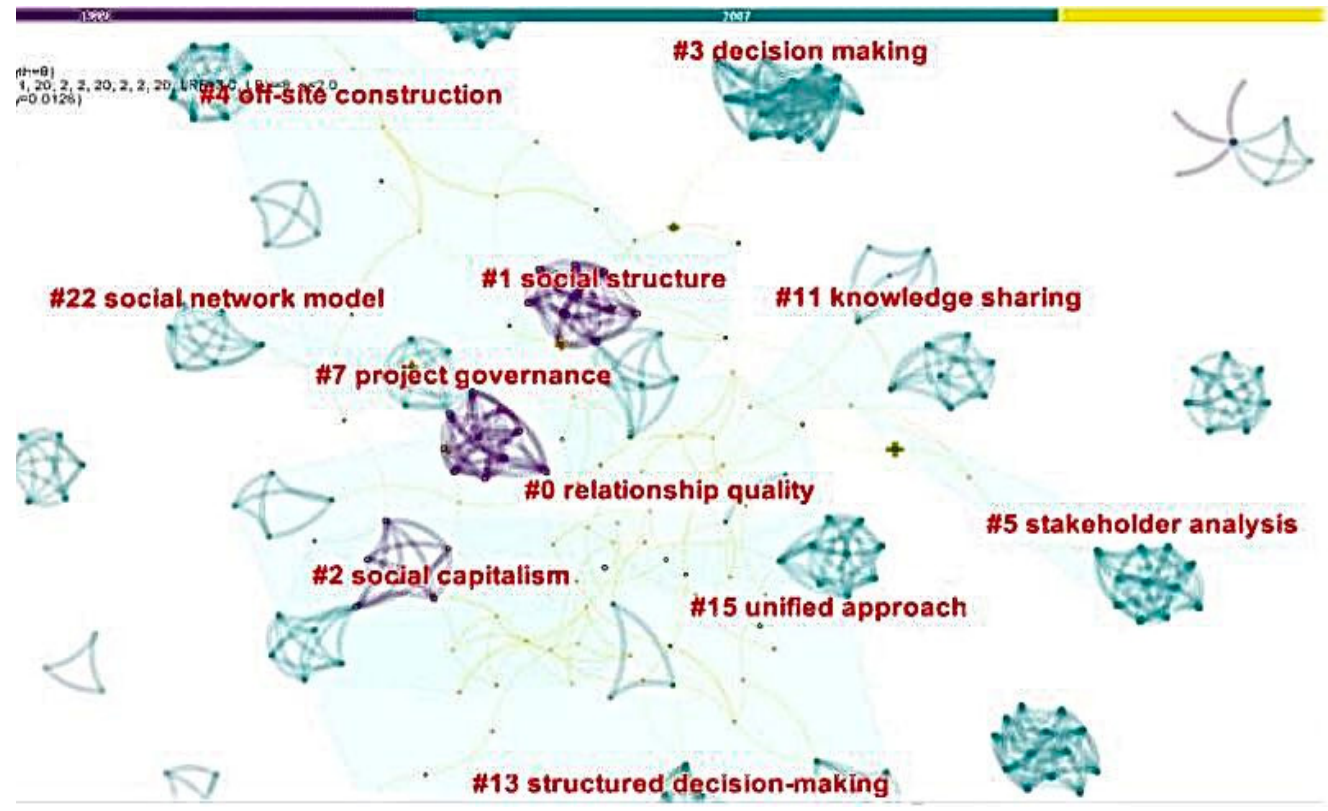

Figure 2 Keyword clustering

Using CiteSpace's cluster explore function to further replace the noise words in the clustering tags and combined with literature reading, the research hotspots in the field of project organization under the SNA perspective were identified with high consistency with the concerns reflected by the keyword co-occurrence: "performance ", "risk", "stakeholders", "communication", and "governance".

\section{Analysis of research trends}

\subsection{Time Zone View Analysis}

Timezone Evolution is a view that shows the evolution of the study from the time dimension, which can clearly show the dynamic changes of the study topic. Set the time zone interval to 5 years and select "Timezone Views" to get the time zone evolution analysis chart shown in Figure 3.

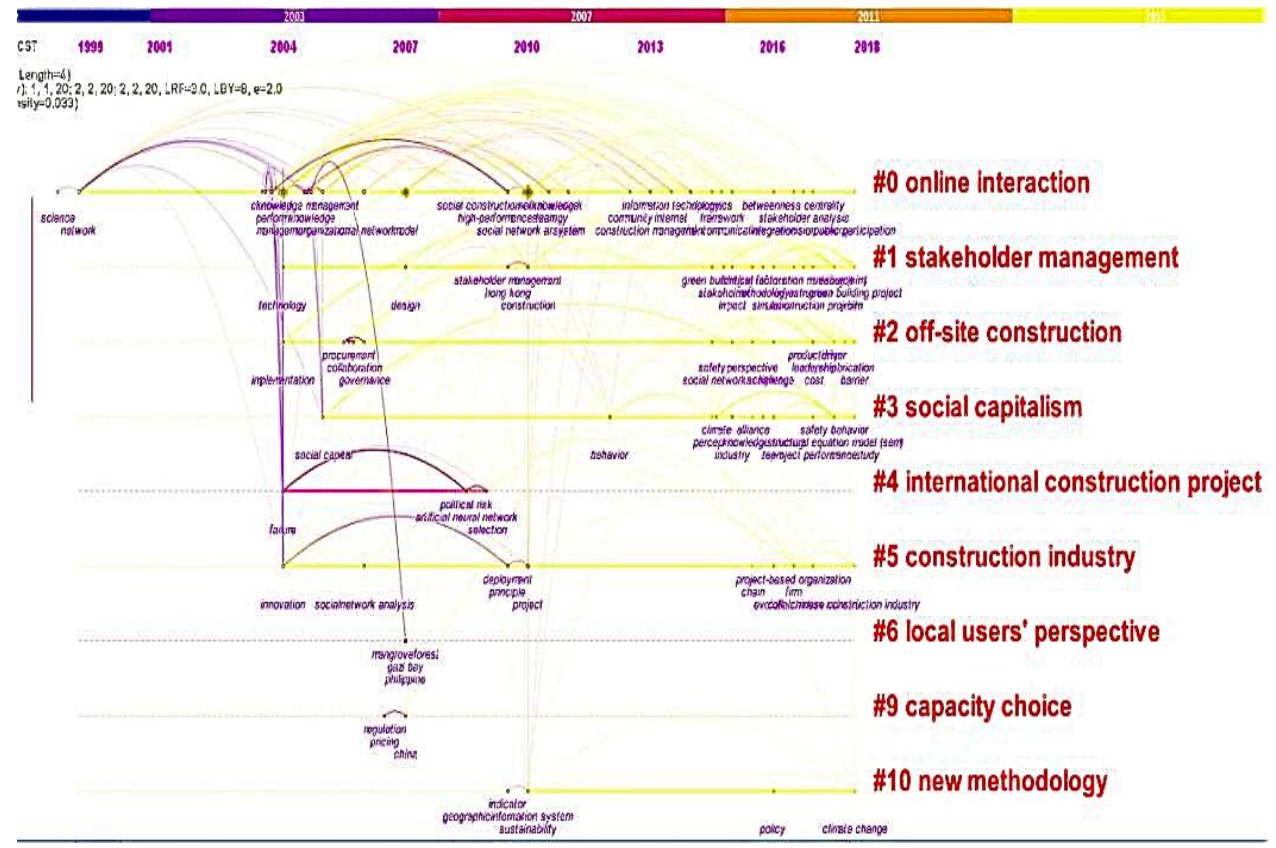

Figure 3 Keyword time zone evolution diagram

Overall, the research in this field has basically formed a process from network description to network action mechanism analysis to network result study. According to the clusters presented in Figure 4 and combined with the research themes of representative literature, it can be found that the relevant research has the characteristics of evolving with time, so the following comprehensive analysis of the subject terms in the clusters by time stage is made as below:

(1)From 1999 to 2010, the research themes were 
mainly focused on the introduction of basic concepts of SNA and the analysis of basic theories. In this period, key words such as "organizational network model" and "organization management" were more central and became the core nodes of research.

(2)In 2011-2016, along with the increasing number of large and complex projects and the gradual recognition of the legitimacy of the social network characteristics of construction project organizations, the complex network relationships within organizations became the focus of research, and the research focus shifted to the different types of network relationships on project performance and the study of subject interaction behavior in the network perspective, etc.

(3)In 2017-2020, the research themes evolved significantly, covering technological innovation cooperation in construction project organizations, the

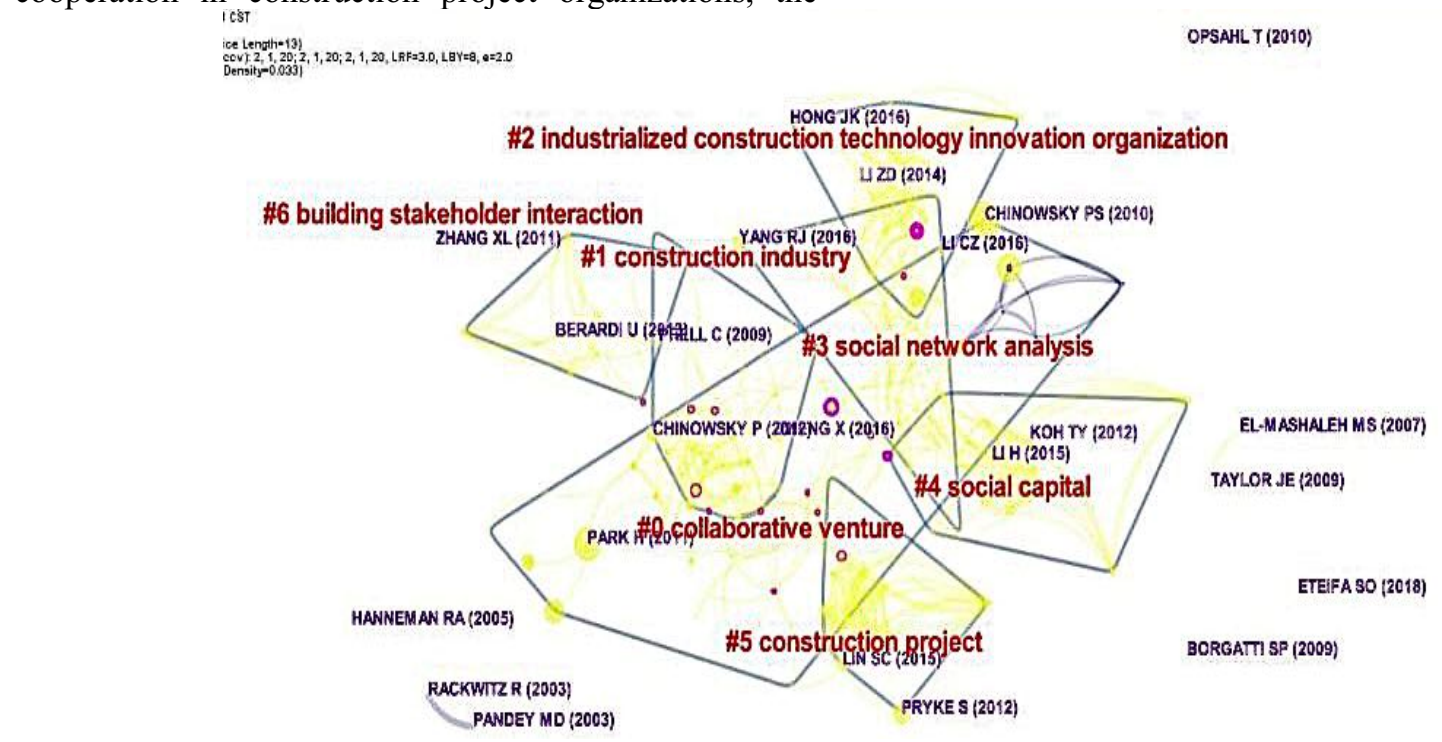

Figure 4 Citation clustering network influence of environmental factors on project members' innovation behavior and innovation performance, and so on. At the same time, "stakeholder management" again becomes the core of research, but the focus of research shifts from the complex relationship between stakeholders to the sharing of responsibilities and risks, and the application of BIM technology.

\subsection{Literature clustering analysis}

Literature co-citation analysis can reveal potential knowledge structures and clusters in research, and a total of seven significant co-citation clusters in the field of construction project research from the SNA perspective were identified based on the similarity between the cited literature (as shown in Figure 4).

To describe these seven co-cited clusters in detail, they

label (LLR), and representative literature, as shown in are further described in terms of Size, Silhouette, Cluster

Table 2.

Table 2 Clustering view indicators of the literature co-citation network

\begin{tabular}{|c|c|c|c|c|c|}
\hline $\begin{array}{c}\text { Cluster } \\
\text { ID }\end{array}$ & Size & Silhouette & \multicolumn{2}{|c|}{ Cluster label (LLR) } & $\begin{array}{c}\text { Representative } \\
\text { Literature }\end{array}$ \\
\hline$\# 0$ & 31 & 0.759 & Original Clustering Label & Replacement labels & H Park \\
\hline$\# 1$ & 25 & 0.896 & collaborative venture & $\begin{array}{c}\text { organizational } \\
\text { competitiveness }\end{array}$ & Keung C \\
\hline$\# 2$ & 20 & 0.879 & construction technology innovation & $\begin{array}{c}\text { Industrialized construction } \\
\text { technology innovation } \\
\text { organization }\end{array}$ & Boland Jr R J \\
\hline$\# 3$ & 18 & 0.808 & $\begin{array}{c}\text { social network analysis } \\
\text { perspective }\end{array}$ & $\begin{array}{c}\text { stakeholder-network } \\
\text { social capital }\end{array}$ & S Missonier \\
\hline$\# 4$ & 17 & 0.902 & social capital & Newell S \\
\hline$\# 5$ & 16 & 0.989 & construction project & safety network & F Wehbe \\
\hline$\# 6$ & 10 & 0.986 & building stakeholder & building stakeholder & Benjamin A \\
\hline
\end{tabular}

According to Table 2 and further analyzed in the context of representative literature: cluster 0 is "collaborative venture", such as H Park et al. study various collaboration models and their impact on project 
performance ${ }^{[9]}$, and other studies discuss the impact of structural and relational embedding on the economic behavior and outcomes of firms ${ }^{[10]}$. Cluster 1 is "organizational competitiveness", and a representative literature of this cluster was published by Keung $\mathrm{C}$ et al. proposing the project collaboration networks can improve their business competitiveness ${ }^{[11]}$, and Cao et al ${ }^{[12]}$. further found that inter-firm relationships The specific association of network structure and organizational competitiveness is related to the attributes of the participants. Cluster 2 focuses on technology innovation organizations, and related studies include technology innovation organizations, green building, and assembly projects. Cluster 4, labeled "social capital," combines interpersonal and network location-related research with in-depth analysis of project relationship governance, knowledge transfer, and performance from a social capital perspective. Cluster 5 is "safety network", which uses social network analysis and visual safety network metrics to assess safety performance and ability to cope with risks. Cluster 3 and Cluster 6 focus on stakeholder interaction or network perspective analysis, respectively, extending traditional analysis methods through a network perspective.

In summary, Cluster 0 and Cluster 1 are grouped under the theme of "Network Effects", Cluster 2 is summarized as "Building Innovation Networks", Cluster 3 and Cluster 6 are unified as "Stakeholders", and Cluster Cluster 4 and Cluster 5 are labeled as "social capital" and "safety networks", respectively.

\section{Conclusion}

This paper presents a visual analysis of the data based on bibliometric and knowledge mapping research methods. The study found that: the overall literature volume in this field has shown a steady increase over a 21-year time span; the visualization analysis further indicates that the research hotspots in this field cover performance, risk, stakeholders, communication, and governance; future research should focus on project organization network innovation, stakeholder relationship governance and risk sharing, BIM technology application, and social capital perspective to improve project.

Future research can be carried out in the following aspects: 1) Transform from the description of construction project organization network to the analysis of construction project organization network structure characteristics and deepen the research on network effects and stakeholders based on that. 2) Strengthen the analysis under the network perspective in the field of construction project organization innovation and expand the research themes of construction innovation network.3) In the above-mentioned research, consider expanding and combining from the overall network research of construction project organization to individual network.

\section{References}

1. Li Y, Lu Y, Kwak Y H, et al. Social network analysis and organizational control in complex projects: construction of EXPO 2010 in China[J]. Engineering
Project Organization Journal, 2011, 1(4): 223-237.

2. CHINOWSKY P S, TAYLOR J E. Networks in engineering: an emerging approach to project organization studies[J]. Engineering Project Organization Journal, 2012, 2(1-2):15-26.

3. ZHENG X, LE Y, CHAN A P C, et al. Review of the Application of Social Network Analysis (SNA) in Construction Project Management Research[J]. International Journal of Project Management, 2016, 34(7):1214-1225.

4. Loosemore M. Construction crises as periods of social adjustment $[\mathrm{J}]$. Journal of management in engineering, 1997, 13(4): 30-37.

5. Son J W, Rojas E M. Evolution of collaboration in temporary project teams: An agent-based modeling and simulation approach[J]. Journal of construction engineering and management, 2010, 137(8): 619-628.

6. Mead S P. Using social network analysis to visualize project teams[J]. Project Management Journal, 2001, 32(4): 32-38.

7. M. Hueskes, K.Verhoest, T.Block , I.J.P.M 35(6), 1184-1195 (2017).

8. DeFillippi R, Sydow J. Project networks: Governance choices and paradoxical tensions[J]. Project Management Journal, 2016, 47(5): 6-17.

9. Park H, Han S H, Rojas E M, et al. Social network analysis of collaborative ventures for overseas construction projects[J]. Journal of construction engineering and management, 2010, 137(5): 344-355.

10. Son J W, Han S H, Rojas E M. Embeddedness and collaborative venture networks among Korean construction firms for overseas construction projects[J]. Journal of Civil Engineering and Management, 2015, 21(4): 478-491.

11. Keung C, Shen L. Network strategy for contractors' business competitiveness[J]. Construction Management and Economics, 2017, 35(8-9): 482-497.

12. Cao D, Li H, Wang G, et al. Relationship network structure and organizational competitiveness: Evidence from BIM implementation practices in the construction industry[J]. Journal of management in engineering, 2018, 34(3): 04018005. 